\title{
Nutrition in the Neurocritical Care Unit: a New Frontier
}

\author{
Tachira Tavarez ${ }^{1, *}$ \\ Kelly Roeht ${ }^{2}$ \\ Lauren Koffman ${ }^{1}$
}

\author{
Address \\ ${ }^{*}, 1$ Department of Neurologic Sciences, Rush University Medical Center, 1725 West \\ Harrison Street Professional Office Building, Suite 1106, Chicago, IL, USA \\ Email: Tachira_Tavarez@rush.edu \\ ${ }^{2}$ Department of Food and Nutrition, Rush University Medical Center, Chicago, IL, \\ USA
}

Published online: 31 March 2021

(C) The Author(s), under exclusive licence to Springer Science+Business Media, LLC, part of Springer Nature 2021

This article is part of the Topical Collection on Critical Care Neurology

Keywords Nutrition support $\cdot$ Neurocritical care $\cdot$ Microbiome $\cdot$ Immunonutrition $\cdot$ Cerebral metabolism $\cdot$ Ketogenic diet

\begin{abstract}
Purpose of Review This review presents the most current recommendations for providing nutrition to the neurocritical care population. This includes updates on initiation of feeding, immunonutrition, and metabolic substrates including ketogenic diet, cerebral microdialysis (CMD) monitoring, and the microbiome.

Recent Findings Little evidence exists to support differences in feeding practices among the neurocritical care population. New areas of interest with limited data include use of immunonutrition, pre/probiotics for microbiome manipulation, ketogenic diet, and use of CMD catheters for substrate utilization monitoring.

Summary Acute neurologic injury incites a cascade of adrenergic and neuroendocrine events resulting in a pro-inflammatory and hypercatabolic state, which is associated with an increase in morbidity and mortality. Nutritional support provides substrates to mitigate the damaging effects of hypermetabolism. Despite this practice, studies on feeding delivery outcomes remain inconsistent. Guidelines suggest use of early enteral nutrition using standard polymeric formulas. Population heterogeneity, variability in interventions, complexities of the metabolic and inflammatory responses, and paucity of nutrition research in patients requiring neurocritical care have led to controversies in the field. It is imperative that more pragmatic and reproducible research be conducted to better understand underlying pathophysiology and develop interventions that may improve outcomes.
\end{abstract}




\section{Introduction}

Critical illness, including acute neurologic injury, is associated with a hypercatabolic state with significant increases in stress hormones and pro-inflammatory cytokines, which is associated with increased morbidity and mortality $[1,2]$. To mitigate the detrimental metabolic response, nutrition support is provided to offer an exogenous fuel source, preserve lean body mass, and prevent malnutrition. Despite this knowledge, critically ill patients are a heterogenous group with varying comorbidities, genetic makeup, disease severity, nutrition risk, and microbiome $[3,4 \bullet \bullet]$, leading to inconsistent feeding outcome data [5]. Researchers generally agree that early enteral feeding improves outcomes, though there is debate regarding dose adequacy and advancement goals [6-8]. Research to support use of specialized feeding practices or specific micronutrients to improve outcomes among the general critical care and neurocritical care populations remain limited, though several promising theories warrant further investigation $[6,9]$. One must also consider the complexities of inflammation and cellular metabolism and their role in delivery of nutrition to critically ill patients.

This review is divided into two main sections: the first focuses on nutritional assessment and the second on nutritional therapies. Within these sections, we describe current nutritional guideline recommendations, cerebral microdialysis as a complementary nutritional monitoring tool, immunomodulating diets, and microbiome changes in critically ill patients.

\section{Diagnostic Evaluation}

\section{Nutrition Assessment among Critically Ill Patients, Including Neurocritical Care Patients}

Malnutrition is more common among neurologically injured patients, likely due to delay in feeding and/or interruptions in nutritional delivery due to hospital transfers, severity of illness, increased metabolic demands, higher incidence of oropharyngeal dysphagia, cognitive dysfunction, reduced level of alertness, and perception deficits [10, 11].To identify the risk for developing complications associated with inadequate nutritional intake, the American Society for Enteral and Parenteral Nutrition (A.S.P.E.N.) and Society of Critical Care Medicine (SCCM) recommend that a validated screening tool be utilized to determine nutritional risk within 24 to $48 \mathrm{~h}$ of admission to an intensive care unit (ICU) [6]. When risk is identified, a comprehensive nutrition assessment should be completed as soon as possible to identify those most likely to benefit from early nutrition intervention when oral intake is anticipated to be insufficient [6]. Several consensus recommendations have been developed for the assessment and diagnosis of malnutrition, which include evaluation of comorbidities, changes in nutritional intake, ability to meet needs (i.e., gastrointestinal (GI) function and risk of dysphagia or aspiration), and changes in body composition (fat and muscle wasting, and presence of edema) [12, 13].

In patients that are unable to provide nutritional history, biochemical markers may offer a better understanding of metabolic state and potential inadequacy of intake prior to admission. Use of serum proteins, such as albumin and preablumin, are not recommended for use in evaluating nutritional intake due to correlation with inflammatory response as negative acute phase respondents [6]. Other serum and urinary biomarkers such as electrolytes and ketones may guide understanding of metabolic response and fuel utilization. Ketones (acetone, acetoacetate, and beta-hydroxybutyrate) are produced through fatty acid oxidation during periods of starvation. This ketonuria should not be mistaken for ketonuria with glucosuria due to poor glycemic control. In 
the absence of glucosuria, ketonuria may indicate inadequate nutritional intake [14]. Positive urinary ketones may suggest reduced intake over several days or longer prior to admission and may be used as an indicator of nutritional adequacy prior to admission, as well as risk for refeeding syndrome.

\section{Metabolic Demands and Substrate Utilization in Neurocritical Care}

Neurologic injury triggers a hypercatabolic state, primarily mediated by glucocorticoids, catecholamines, and glucagon [15]. Resting energy expenditure (REE) has been found to be as high as $200 \%$ of usual needs in two-thirds of patients during the first 2 to 4 weeks following brain trauma $[1,10,16]$. Energy requirements of patients with stroke vary widely depending on stroke type [17]. Elevated REE in patients with higher grade aneurysmal subarachnoid hemorrhage (SAH) has been associated with higher incidence of vasospasm [18-20]. Additionally, metabolic demands may vary throughout the ICU course as various therapies common in neurocritical care influence metabolic demands including the use of barbiturates, sedation, normothermia, and hypothermia $[15,21]$.

Indirect calorimetry (IC) is the gold standard and recommended method to determine energy requirements in the critically ill population [6]. IC uses the amount of oxygen and carbon dioxide consumed to provide a measurement of REE, which is then extrapolated over a $24 \mathrm{~h}$ time period. IC is advantageous because it is non-invasive while providing real-time information of energy requirements in circumstances when equations for predicting REE are unreliable [21]. For example, sedating medications and paralytics make predicting REE with IC unreliable. Use of IC may be limited by the need for high positive pressure and oxygen settings among those requiring mechanical ventilation, also in patient who require use of non-invasive mechanical ventilation, continuous renal replacement therapy, extracorporeal membrane oxygen exchange (ECMO), and chest tubes with poor seals [21]. Unfortunately, IC is costly, labor intensive, and requires specially trained clinicians to perform and interpret the measurement. For these reasons, it is rarely used in clinical practice, but if done, should be repeated routinely as conditions change to ensure that the measurement accurately reflects the patient's current metabolic state to prevent under or overfeeding.

In addition to an increase in REE, metabolic processes such as glycogenolysis and gluconeogenesis result in concomitant hyperglycemia and increased skeletal protein catabolism [15]. This elevated protein catabolism in the setting of inadequate nutritional intake or delivery may result in a negative nitrogen balance, reflecting the loss of total body protein [16]. Traumatic brain injury (TBI) patients have shown altered energy metabolism for weeks after injury

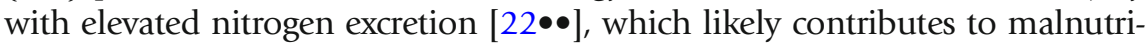
tion. This catabolic derangement is associated with an increase odd of 30- and 90 -day mortality and $40 \%$ increased odds of 365-day post-discharge mortality,

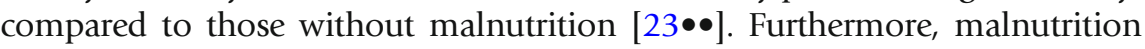
with negative nitrogen balances and altered C-reactive protein (CRP) and transthyretin (TTR) ratios have been associated with significantly more hospitalacquired infections and worse neurologic outcomes in this population [24•]. Greater than $40 \%$ of patients with ischemic stroke (IS) have been found to have a negative nitrogen balance [25], suggesting catabolism and malnutrition. 
Malnutrition has been observed in $16 \%$ of patients with IS upon admission, increasing to $26 \% 1$ week following stroke occurrence [26]. Factors associated with increased risk for having or developing malnutrition after IS include cognitive deficits, upper extremity paresis, impaired self-feeding ability, apraxia, depression, prior stroke, diabetes, dysphagia, and need for enteral nutrition [27].

No individual tool can provide a complete picture of a patient's nutritional needs. Multiple monitoring strategies with frequent evaluations, along with participation of an integrated nutritional team allow for a complete assessment of the patient's nutritional needs.

Metabolic Substrates: a Role for Cerebral Microdialysis Monitoring

A healthy human brain, while only $2-3 \%$ of the total body weight, consumes $20 \%$ of the total oxygen and $25 \%$ of total glucose available to the body. Glucose is the preferred fuel source when available, and the brain is unable to store or produce glucose, and as an adaptive response can metabolize other substrates may be metabolized for ATP production. These substrates include ketone

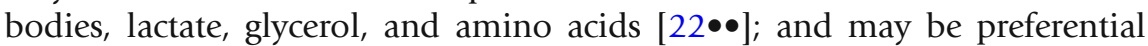
substrates during cerebral energetic crisis to minimize potential deleterious effects associated with hyperglycemia and aggressive insulin therapy leading

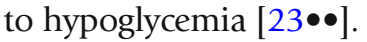

Cerebral microdialysis (CMD) is an invasive parenchymal monitor that provides insight into the nuances of cerebral metabolism, and allows for the study of real-time substance concentrations within brain tissue and can be implemented as a tool for multimodal monitoring [15].

Limitations often discussed in using CMD are whether or not data from these catheters reflect a regional versus global picture, or if any interventions equally effect normal brain tissue [17]. Despite limitations, CMD research has allowed for the understanding that there are pathologic patterns, such as high CMD lactate-to-pyruvate ratio (LPR) and low CMD glucose, which are associated with increased mortality [15]. Only a few studies describe the effects of nutritional interventions on these markers. $\mathrm{CMD}$ has been used to evaluate brain substrate availability in SAH [17] and TBI populations [18-20]. Kofler et al. reported that in patients with aneurysmal SAH, serum glucose was associated with CMD glucose concentration, and that providing enteral nutrition increases CMD glucose including in the setting of neuroglucopenia [17]. Availability of alternative brain fuel sources has also been described among the TBI population. Researchers reported that TBI patients administered sodium lactic acid experienced an increase CMD pyruvate, an indication of substrate utilization, and an increase availability of brain glucose [24•]. This suggests a potential advantage of using hypertonic lactate as opposed to hypertonic sodium chloride, not only because of the potential metabolic advantages but also to avoid hyperchloremic acidosis [24•]. Additionally, Bernini and colleagues used CMD to study ketone metabolism in TBI patients and found that although cerebral ketone body levels were not associated with cerebral glucose, they were associated with cerebral glutamate, lactate, and pyruvate. These findings suggest that in the setting of metabolic crisis, the brain produces ketone bodies to serve as an alternate source of energy [20]. This is consistent with known astrocyte 


\section{Treatments}

production of ketone bodies from fatty acid oxidation or catabolism of amino acids [25].

Unfortunately, no studies directly establish how CMD guided nutritional interventions impact outcomes such as morbidity and mortality. Given what we understand about cerebral metabolism and the use of alternative substrates in the setting of acute injury, there is potential in using nutritional interventions such as the ketogenic diet. And in the case of super-refractory status epilepticus, use of a ketogenic diet has been shown to be safe and efficacious [26].

\section{Nutrition Initiation, Advancement, and Monitoring}

For those at high nutritional risk that are unable to meet needs orally, early enteral nutrition (EN) should be initiated within 24-48 h of admission, and advanced as quickly as tolerated toward goal of $>80 \%$ of estimated or measured energy and protein requirements over the next 7 days [6]. Early EN supports the functional integrity of the endothelial cells and junctions within the gut, the associated gut-associated lymphoid tissue (GALT), and the downstream mucosal-associated lymphoid tissue (MALT). Inadequate nutritional delivery during the acute inflammatory state may result in bacterial translocation, increase risk for systemic infection and inflammation, and likelihood of multiple organ dysfunction. All of these factors contribute to increasing risk of morbidity and mortality [6]. For patients with adequate baseline nutritional status on admission, guidelines suggest that supplemental parenteral nutrition (PN) be considered after 7-10 days of inadequate intake via oral or enteral route ( $<60 \%$ of requirements), but has not been shown to improve outcomes and may be detrimental if initiated prior to this time period [6]. However, PN is recommended in those with high risk or severe malnutrition on initial assessment as soon as possible following ICU admission when oral or enteral routes are not feasible.

Much of the literature encouraging use of nutrition support among critically ill patients is under the assumption that increased delivery improves outcomes, such as reduced infection rates and LOS, when early goal feeds are achieved. However, the majority of these results are from observational studies or clinical trials with small sample sizes $[27,28]$. Multiple large prospective randomized controlled trials (RCTs) have failed to demonstrate these benefits and suggest increased mortality with higher energy delivery [7, 8, 29-37]. Disruption of autophagy and subsequent alterations in mitochondrial function have been suggested as potential mechanisms by which exogenous nutrient delivery may worsen outcomes $[7,8]$. Significant debate exists within the nutrition support community with regard to how much and how quickly to advance calorie delivery critically ill patients, thus care must be taken to optimize nutrient delivery and to prevent overfeeding. For these reasons, use of repeated measures IC or simplistic predictive equations are recommended when determining needs and feeding goals [6].

Evaluation of gastric residual volumes (GRVs) remains a controversial topic. The most current guidelines recommend against using GRVs due to lack of correlation with incidence of pneumonia, regurgitation, or aspiration [6]. A RCT conducted by Reigneir and colleagues in 2013 found that not checking GRVs did not lead to increased incidence of ventilator associated pneumonia in 
critically ill patients requiring mechanical ventilation $[6,38]$. Patients receiving vasopressor therapy with symptoms of gastrointestinal feeding intolerance (abdominal distension, increased nasogastric tube output, hypoactive bowel sounds, decreased motility or passage of stool, metabolic acidosis, and/or base deficit) should be monitored for early signs of ischemic bowel, holding EN until condition stabilizes or improves [6].

Ongoing monitoring and evaluation of energy, protein, fluid, and electrolyte requirements, and adequacy of intake in relation to needs should be conducted throughout the ICU and hospital stay. These processes prevent overfeeding and potential for increased mortality, as well as chronic underfeeding and development of malnutrition. This can be achieved by early involvement by the nutrition support team to implement and continue to monitor tolerance and appropriateness of nutrition interventions.

\section{Ketogenic Therapy Among Neurocritical Care Populations}

Ketogenic diets (KDs) alter human metabolism with parallel synergistic effects, including alterations in energy metabolism (decrease in glycolysis, increase in fatty acid oxidation with ketone production) and alterations in neurotransmitter production, release and uptake [39-41]. A review of TBI animal models suggests KDs reduce cerebral edema, apoptosis, improves cerebral metabolism, and behavioral outcomes in rodents [42]. KDs and their modified forms have been found to reduce seizure frequency by approximately $50 \%$ in both pediatric and adult populations regardless of seizure type [43-45], efficacy similar to that of medications. A recent systematic review on use of KDs among adult patients with status epilepticus (SE) demonstrated safety and efficacy as adjuvant therapy in SE treatment [46], although should be interpreted with caution due to small sample sizes. Ketogenic diet has been shown to be a feasible and safe therapy for super-refractory status epilepticus (SRSE) [26]. Of the 14 patients that completed treatment, SRSE was resolved in 11 patients in a median of 5 days. Given the overall safety of administering KDs and their multiple therapeutic targets, they are a promising adjunct therapy for multiple acute neurologic pathologies.

Diets high in processed carbohydrates and fats and low in fiber and micronutrients contribute to a pro-inflammatory state that underlies the development of many chronic diseases [47-49]. Comparatively, diets rich in minimally processed, nutrient-dense foods are associated with long-term health [47-49]. The mechanisms involved are multifactorial and beyond the scope of this review, though are the basis for the theory that nutrients can modulate the immune and inflammatory response [50], often referred to as "immunonutrition." Potential mechanisms for immune-modulating effects include delivery of specific amino acids as preferred fuel sources for enterocytes, omega-3 (n-3)rich polyunsaturated fatty acids (PUFAs) to manipulate eicosanoid production and downstream anti-inflammatory cytokine response [50,51], as well as reducing oxidative stress through delivery of specific vitamins, minerals, and phytochemicals involved in human antioxidant systems [50] (Table 1).

Immunonutrition attempts to modulate the immune response by altering nutrients involved in the inflammatory process, and has been studied in various 
Table 1. Proposed mechanisms of immune-modulating nutrients

\begin{tabular}{|c|c|}
\hline Nutrient & Proposed mechanism of immune modulation \\
\hline \multicolumn{2}{|l|}{ Amino acids } \\
\hline Glutamine & $\begin{array}{l}\text { Primary fuel source for enterocytes, lymphocytes, macrophages; conditionally } \\
\text { essential during metabolic stress }\end{array}$ \\
\hline Arginine & $\begin{array}{l}\text { Conditionally essential amino acid during metabolic stress; required for normal T- } \\
\text { and B lymphocyte and macrophage function }\end{array}$ \\
\hline \multicolumn{2}{|l|}{ Fatty acids } \\
\hline $\begin{array}{l}\text { Eicosapentaeoic acid (EPA) and Doco- } \\
\text { sahexaenoic acid (DHA) }\end{array}$ & $\begin{array}{l}\text { Less pro-inflammatory cytokine response with potential to reduce impact of the } \\
\text { eicosanoids, prostaglandins, leukotrienes, and thromboxanes produced omega- } 6 \\
\text { fatty acids }\end{array}$ \\
\hline \multicolumn{2}{|l|}{ Antioxidants } \\
\hline $\begin{array}{r}\text { Vitamin } C \text {, vitamin } E \text {, beta-carotene, } \\
\text { selenium, and zinc }\end{array}$ & $\begin{array}{l}\text { Antioxidant effect reducing oxidative stress at cellular level by enhancing } \\
\text { superoxide dismutase, glutathione peroxidase }\end{array}$ \\
\hline [51] & \\
\hline
\end{tabular}

critically ill populations, including those in neurocritical care. Nutrients involved in immunonutrition research include various macronutrients such as amino acids glutamine and arginine, and $n-3$ fatty acids and micronutrients such as vitamin $\mathrm{C}$, zinc, and selenium (Table 1). Given the complexity of the pathophysiologic pathways leading to secondary injury, various micronutrients have been suggested for their potential to impart a therapeutic effect on outcomes associated with critically ill patients. The primary targets of immunonutrition therapy include the mucosal barrier, cellular immune defenses, and both local and systemic inflammatory responses [50].

Micronutrients have been shown to have a variety of mechanisms and overall low toxicity, making them an attractive candidate for supplemental therapies in patients with neurologic injury [52]. While beyond the scope of this review, researchers have previously summarized outcomes associated with micronutrient delivery among the neurologically impaired population (Table 2). Use of immune-enhancing enteral products has not shown to improve outcomes comparted to standard formulas, and are not recommended for routine use among the general ICU populations [6]. Despite lack of outcomes related to morbidity or mortality, consensus guidelines site low-grade evidence for use of either arginine-containing immune-modulating formulations or EPA/DHA supplementation with standard EN in those with TBI [6], suggesting use may be beneficial. These recommendations are based on results from one study [58].

Use of glutamate and probiotics were simultaneously studied in a small RCT in patients with brain injuries [58]. Researchers reported fewer infections, fewer mechanical ventilation days, and shorter ICU LOS among those receiving a glutamine and probiotic enriched formula $(n=5)$ compared to those in an isocaloric, isonitrogenous control $(n=5)$. While this warrants further investigation, the study was limited by small sample size and inadequate power to detect these differences for the reported outcomes. Another limitation was that the intervention contained both immune-modulating nutrients and probiotics, 


\begin{tabular}{|c|c|c|}
\hline Micronutrient & $\begin{array}{l}\text { Patient } \\
\text { population }\end{array}$ & Findings \\
\hline $\begin{array}{l}\text { Vitamin } C \text { and } E \\
\text { [53] }\end{array}$ & $\begin{array}{l}\text { Traumatic brain } \\
\text { injury }\end{array}$ & $\begin{array}{l}\text { - Vitamin E was associated with improved mortality and GCS scores at discharge } \\
\text { - High-dose vitamin C was associated with stabilization of perilesional edema }\end{array}$ \\
\hline Vitamin D [54] & Ischemic stroke & $\begin{array}{l}\text { - Associated with increased survival at } 6 \text { months and a trend toward improved } \\
\text { functional outcome at } 6 \text { months }\end{array}$ \\
\hline $\begin{array}{l}\text { Vitamin D and } \\
\text { progesterone } \\
\text { [55] }\end{array}$ & $\begin{array}{l}\text { Acute spinal cord } \\
\text { injury }\end{array}$ & $\begin{array}{l}\text { - Associated with significant improvement in motor and sensory American Spinal } \\
\text { Injury Association impairment scale (AIS) scores }\end{array}$ \\
\hline Magnesium [56] & $\begin{array}{l}\text { Subarachnoid } \\
\text { hemorrhage }\end{array}$ & $\begin{array}{l}\text { - Significant decrease in occurrence of vasospasm, delayed cerebral ischemia, } \\
\text { and secondary infarction in the intervention group }\end{array}$ \\
\hline $\begin{array}{l}\text { Ketogenic diet [26, } \\
\text { 57] }\end{array}$ & $\begin{array}{l}\text { Acute spinal cord } \\
\text { injury, SRSE }\end{array}$ & $\begin{array}{l}\text { - Significant improvement on motor and sensory scores in AIS and improvement } \\
\text { in inflammatory markers } \\
\text { - Safe and efficacious in the resolution of SRSE }\end{array}$ \\
\hline
\end{tabular}

making it difficult to determine if the beneficial mechanism was related to immunonutrition or changes in the microbiome. Another RCT aimed to evaluate the effect of an immunonutrition enteral formula containing arginine, glutamine, and omega-3 fatty acids on serum biomarkers (IL-6, glutathione, CRP, albumin, and total protein) among patients with TBI [59]. Although those receiving the immune-enhancing formula were found to have a concurrent reduction in serum IL-6 and rise in glutathione compared to control, morbidity, and mortality outcomes were not reported.

Fatty acids, specifically n-3 PUFAs including DHA and EPA, have shown promising results in preclinical studies [52], though translation to clinical research is limited. Theoretic benefits include a reduction in inflammatory and oxidative responses, antithrombotic effects, and improved maintenance of tissue micro perfusion [50,52]. The effect of daily administration of $n-3$ supplementation (via EPA, mixed EPA/DHA, and EN containing EPA/DHA) during the vasospasm window following $\mathrm{SAH}$ has been found to have significantly fewer occurrences of vasospasm [60, 61], infarcts [61], and more favorable outcomes [60]. However, these studies are limited by lack of consistency in supplementation dose and type, thus it is unclear whether participants received the intended doses as many did not achieve target volume feedings containing the immune-modulating nutrients.

Outcomes of immunonutrition research in the neurocritical care population is similar to that of the general ICU population and is limited by heterogeneity, dose response, outcome measures, as well as inadequate sample size. Additionally, use of certain nutrients ( $n-3$ and arginine) has been demonstrated to potentially increase risk for harm [6]. Common criticisms include heterogeneity of populations, underreporting with regard to actual nutrient delivery compared to goal doses, unclear demonstration of changes in biomarkers and clinical outcomes, as well as differences in other nutrition-related outcomes (i.e., macronutrient delivery). These factors make it difficult to interpret whether beneficial effects are due to nutritional intake as a whole or due to delivery of 
immune-enhancing components [51]. Additional research is needed with larger sample sizes, reporting of delivery and biomarkers, and assessment of clinical outcomes before routine use among the neurocritical care population can be recommended.

The Microbiome and the Gut-Brain Axis-Implications Relating to Nutrition, Inflammation, and Critical Illness

The microbiome describes the species and genetic profile of the microorganisms living in and on the human body, with the largest number residing within the gut. The microbiome influences the development of many diseases, including those of the enteric nervous system (ENS) and central nervous system (CNS) through modulation of the "gut-brain axis [62]." Examples of these include motility disorders, behavioral disorders, neurodegenerative disease, cerebrovascular injury, and neuroimmune-mediated disorders [62]. Potential influences of the microbiome include, but are not limited to: alterations in hypothalamicpituitary-adrenal axis [63], vagal nerve stimulation [64, 65], SCFA activation of microglial cells [66], changes in permeability of the blood brain barrier [67], modulation of host biosynthesis pathways, and production/modulation of neuroendocrine hormones such as gamma-amino butyric acid (GABA) and serotonin [62].

Two large phylogenic types dominate the commensal bacteria of a healthy gut: Firmicutes and Bacteroidetes [68]. Under healthy conditions these microbiota play crucial roles in maintaining host (human) metabolism, production of short-chain fatty acids (SCFAs), micronutrient production, immunocompetence, gut integrity, and colonization resistance [3]. Disruption of microbiome homeostasis-described as dysbiosis or pathobiome-is characterized as a shift to low within group (alpha) diversity and high between group (beta) diversity with decreases in the beneficial species of Firmicutes and Bacteroidetes, including those that produce SCFAs, and rises in Proteobacteria $[3,4 \bullet \bullet]$. This shift may be equally or more important than the host's genetics in development of many chronic diseases mediated by chronic inflammation, including inflammatory bowel disease, obesity, diabetes, and cardiovascular disease [47-49].

Dietary patterns associated with low intake of processed foods and high intake of prebiotic fibers (i.e., fructooligosaccharides and inulin naturally found in non-starchy vegetables) offer a fermentable fuel source to support growth of commensal microbes capable of producing SCFAs, such as Bifidobacteria and Lactobacillus [35]. Pro-inflammatory diets low in fiber, and high in fat, protein, and sugar have been found to reduce SCFA production, shifting to a proinflammatory microbiome profile [69]. Pro-inflammatory bacteria may exacerbate endoxotemia and inflammation by increasing transport of lipopolysaccharides (LPSs), structures present on the outer membrane of gram-negative bacteria that exert immunogenic effects. One of those effects is activation of tolllike receptor (TLR)-4, a receptor that upregulates transcription of proinflammatory cytokines [70].

It has been hypothesized that the gut is the "motor" of multiple organ dysfunction syndrome in critical illness due to complex interactions between the gut epithelium and immune system, $[71-73,74 \bullet]$. Critical illness alone has been found to induce profound shifts toward a pathogenic microbiome within hours of admission to the ICU $[75,76]$, which is exacerbated by medications 
that significantly impact the microbiomeincluding antibiotics, opioids, and proton pump inhibitors [77-79]. Commensal microbiota help to metabolize medications, nutrients, and hormones, modulate immune responses, and maintain mucosal barrier homeostasis [48]. Therefore a disruption during critical illness may increase risk for invasion of pathogenic bacteria, including bacterial translocation [70]. The dysbiosis worsens and shifts toward more pathogenic microbiota with longer ICU duration [80-83]. This has also been demonstrated in neurocritical care populations, including animal and human models of TBI and spinal cord injury [84-86]. It has been suggested that serial changes in the ratios of beneficial species of Firmicutes/Bacteroidetes can potentially predict patient outcomes [80].

Patients in the neurocritical care unit are at high risk for developing nutrition-related complications, including malnutrition and worse clinical outcomes. Identification of nutrition risk through appropriate assessment to identify pre-existing malnutrition should occur as soon as possible following ICU admission to determine when and which type of nutrition intervention may offer the most benefit.

\section{Critical Care Interventions Impacting the Microbiome}

While a pathogenic microbiome has been described among critically ill patients, there is very little evidence to demonstrate that nutrition administration during critical illness impacts the microbiome of critically ill patients. The available literature focuses on modulation of the microbiome through administration of pre- and probiotics to improve GI alterations (i.e. diarrhea); however, variability in fiber composition and bacterial species have yielded mixed results. Consensus guidelines suggest use of a probiotic soluble fiber for diarrhea treatment over use of mixed-fiber formulas, citing fermentation and production of SCFAs [6].

Withholding enteral nutrition in the setting of critical illness is associated with alterations in microbiome composition and impaired epithelial barrier function with subsequent bacterial translocation and sepsis [87-89]. The effect of EN and pre- and probiotic supplementation, as well as SCFAs delivery among neurologically injured patients has been described.

One group of researchers examined the differences in energy delivery, complications, and biochemical markers (including CRP) among a heterogenous group of neurocritical care patients randomized to receive standard enteral formula versus enteral formula-containing probiotics [90]. No significant differences were found in achievement of target energy delivery or inflammatory outcomes between groups, though those receiving EN with probiotics were found to require less insulin and have lower rates of diarrhea. In another study conducted among patients with severe TBI receiving EN, with and without probiotic supplementation, serum inflammatory markers (IL-6, Il-10, TNFalpha, and CRP) were reported to decrease more significantly among patients receiving a probiotic containing Bifidobacterium, Lactobacillus, and Enterococcus faecalis [91].

Bypassing the delivery of probiotics capable of producing SCFAs, one group administered SCFAs in a post-stroke recovery mouse model, demonstrating improved recovery of motor function, as well as in vivo, finding changes in synapse density and microglial activation dependent on $\mathrm{T}$ cell recruitment in 


\section{Conclusion}

infarcted brain cells [92]. This suggests that microbiota-derived SCFA may modulate post-stroke recovery though systemic and immunologic effects [92].

Perhaps the inability to demonstrate significant microbiome or inflammatory modulation among critically ill patients is related to pre-admission dysbiosis associated with a pro-inflammatory diet and microbiome. Manufacturers of nutrition support products have incorporated specific nutrients and compounds to enhance the immune response and microbiome. However, standard polymeric enteral formulas do not resemble whole-food diets, and typically lack the beneficial phytochemicals that have been found to impact long-term health through various inflammatory pathways, including the gut microbiota and gut integrity [93]. It is possible that whole-food-based nutrition therapy may offer beneficial outcomes on morbidity and mortality among critically ill populations. However, safety and efficacy to modulate the immune response should first be evaluated among the general healthy population given concerns for infection risk with blenderized, whole-food feedings without safe foodhandling practices [94].

There is likely a synergistic effect between diet quality, gut microbiome, and inflammatory response mechanisms. Much attention has been paid to the impact of macronutrient and micronutrient composition, the processing on digestibility and fermentability of nutrients, the presence of phytochemicals or lack thereof, and fasting on the human microbiome and inflammatory responses. The ability to modulate these effects is a crucial factor in improving human health long-term health, as well as those with critical illness and neurologic injury. Despite current research revealing the potential therapeutic benefits of different aspects of nutrition therapy, the exact mechanisms of nutrition are not fully understood likely due to the complex interactions and evolving food diversity and microbiota species. More pragmatic, randomized control trials are necessary to provide high levels of evidence for future recommendations, especially within the neurocritical care population.

\section{References and Recommended Reading}

Papers of particular interest, published recently, have been highlighted as:

- Of importance

$\bullet \quad$ Of major importance

1. Foley N, Marshall S, Pikul J, Salter K, Teasell R. Hypermetabolism following moderate to severe traumatic acute brain injury: a systematic review. J Neurotrauma. 2008;25(12):1415-31. https://doi.org/10.1089/neu. 2008.0628.

2. Helmy A, Carpenter KL, Menon DK, Pickard JD, Hutchinson PJ. The cytokine response to human traumatic brain injury: temporal profiles and evidence for cerebral parenchymal production. J Cereb Blood Flow Metab. 2011;31(2):658-70. https://doi.org/10.1038/ jcbfm.2010.142.

3. Oami T, Chihade DB, Coopersmith CM. The microbiome and nutrition in critical illness. Curr Opin Crit Care. 2019;25(2):145-9. https://doi.org/10.1097/mcc. 0000000000000582. 
4.• Moron R, Galvez J, Colmenero M, Anderson P, Cabeza $\mathrm{J}$, Rodriguez-Cabezas ME. The importance of the microbiome in critically ill patients: role of nutrition. Nutrients. 2019;11(12). https://doi.org/10.3390/ nu11123002.

Review of microbiome changes among critically ill patients, as well as research on nutritional strategies to modulate the gut microbiome.

5. Peterson SJ, McKeever L, Lateef OB, Freels S, Fantuzzi G, Braunschweig CA. Combination of high-calorie delivery and organ failure increases mortality among patients with acute respiratory distress syndrome. Crit Care Med. 2019;47(1):69-75. https://doi.org/10. $1097 / \mathrm{ccm} .0000000000003476$.

6. McClave SA, Taylor BE, Martindale R, Warren MM, Johnson DR, Braunschweig C, et al. Guidelines for the provision and assessment of nutrition support therapy in the adult critically ill patient: Society of Critical Care Medicine (SCCM) and American Society for Parenteral and Enteral Nutrition (ASPEN). J Parenter Enter Nutr. 2016;40(2):159-211.

7. Braunschweig CL, Freels S, Sheean PM, Peterson SJ, Perez SG, McKeever L, et al. Role of timing and dose of energy received in patients with acute lung injury on mortality in the intensive nutrition in acute lung injury trial (INTACT): a post hoc analysis. Am J Clin Nutr. 2017;105(2):411-6. https://doi.org/10.3945/ajcn. 116.140764

8. Peterson SJ, Lateef OB, Freels S, McKeever L, Fantuzzi G, Braunschweig CA. Early exposure to recommended calorie delivery in the intensive care unit is associated with increased mortality in patients with acute respiratory distress syndrome. JPEN J Parenter Enteral Nutr. 2018;42(4):739-47. https://doi.org/10.1177/ 0148607117713483.

9. Carney N, Totten AM, O'Reilly C, Ullman JS, Hawryluk GW, Bell MJ, et al. guidelines for the management of severe traumatic brain injury, Fourth Edition. Neurosurgery. 2017;80(1):6-15. https://doi.org/10.1227/ neu.0000000000001432.

10. Chapple LS, Deane AM, Heyland DK, Lange K, Kranz AJ, Williams LT, et al. Energy and protein deficits throughout hospitalization in patients admitted with a traumatic brain injury. Clin Nutr. 2016;35(6):131522. https://doi.org/10.1016/j.clnu.2016.02.009.

11. Burgos R, Breton I, Cereda E, Desport JC, Dziewas R, Genton $\mathrm{L}$, et al. ESPEN guideline clinical nutrition in neurology. Clin Nutr. 2018;37(1):354-96. https://doi. org/10.1016/j.clnu.2017.09.003.

12. White JV, Guenter P, Jensen G, Malone A, Schofield M. Consensus statement: Academy of Nutrition and Dietetics and American Society for Parenteral and Enteral Nutrition: characteristics recommended for the identification and documentation of adult malnutrition (undernutrition). JPEN J Parenter Enteral Nutr. 2012;36(3):275-83. https://doi.org/10.1177/ 0148607112440285 .

13. Cederholm T, Jensen GL, Correia M, Gonzalez MC, Fukushima R, Higashiguchi T, et al. GLIM criteria for the diagnosis of malnutrition - a consensus report from the global clinical nutrition community. Clin Nutr. 2019;38(1):1-9. https://doi.org/10.1016/j.clnu.2018. 08.002 .

14. Selberg O, Sel S. The adjunctive value of routine biochemistry in nutritional assessment of hospitalized patients. Clin Nutr. 2001;20(6):477-85. https://doi. org/10.1054/clnu.2001.0427.

15. Kurtz P, Rocha EEM. Nutrition therapy, glucose control, and brain metabolism in traumatic brain injury: a multimodal monitoring approach. Front Neurosci. 2020;14:190. https://doi.org/10.3389/fnins.2020. 00190.

16. Dickerson RN. Nitrogen balance and protein requirements for critically ill older patients. Nutrients. 2016;8(4):226. https://doi.org/10.3390/nu8040226.

17. Kofler M, Schiefecker AJ, Beer R, Gaasch M, Rhomberg $\mathrm{P}$, Stover J, et al. Enteral nutrition increases interstitial brain glucose levels in poor-grade subarachnoid hemorrhage patients. J Cereb Blood Flow Metab. 2018;38(3):518-27. https://doi.org/10.1177/ 0271678 X17700434.

18. Glenn TC, Martin NA, Horning MA, McArthur DL, Hovda DA, Vespa P, et al. Lactate: brain fuel in human traumatic brain injury: a comparison with normal healthy control subjects. J Neurotrauma. 2015;32(11):820-32. https://doi.org/10.1089/neu. 2014.3483.

19. Patet C, Suys T, Carteron L, Oddo M. Cerebral lactate metabolism after traumatic brain injury. Curr Neurol Neurosci Rep. 2016;16(4):31. https://doi.org/10. 1007/s11910-016-0638-5.

20. Bernini A, Masoodi M, Solari D, Miroz JP, Carteron L, Christinat N, et al. Modulation of cerebral ketone metabolism following traumatic brain injury in humans. J Cereb Blood Flow Metab. 2020;40(1):177-86. https:// doi.org/10.1177/0271678X18808947.

21. Delsoglio M, Achamrah N, Berger MM, Pichard C. Indirect calorimetry in clinical practice. J Clin Med. 2019;8(9). https://doi.org/10.3390/jcm8091387.

22.• Abdelmalik PA, Dempsey S, Ziai W. Nutritional and bioenergetic considerations in critically ill patients with acute neurological injury. Neurocrit Care. 2017;27(2):276-86. https://doi.org/10.1007/s12028016-0336-9

An important review focusing on substrate metabolism and energy requirements in the neurocritical care population.

23.• Quintard H, Ichai C. Nutritional and metabolic supplementation for the injured brain: an update. Curr Opin Crit Care. 2019;25(2):126-31. https://doi.org/ $10.1097 / \mathrm{mcc} .0000000000000588$

Review of the role of nutrition, including energy requirements, delivery of nutrition, and researched supplementation strategies on outcomes among TBI patients.

24. Oddo M, Vespa P, Menon DK. Boosting the injured brain with supplemental energy fuels. Intens Care Med. 2019;45(6):872-5. https://doi.org/10.1007/s00134018-05517-6 
A brief review of regarding ketones and lactate as alternate sources of energy for the brain.

25. Achanta LB, Rowlands BD, Thomas DS, Housley GD, Rae CD. $\beta$-Hydroxybutyrate boosts mitochondrial and neuronal metabolism but is not preferred over glucose under activated conditions. Neurochem Res. 2017;42(6):1710-23. https://doi.org/10.1007/ s11064-017-2228-6.

26. Cervenka MC, Hocker S, Koenig M, Bar B, HenryBarron B, Kossoff EH, et al. Phase I/II multicenter ketogenic diet study for adult superrefractory status epilepticus. Neurology. 2017;88(10):938-43. https:// doi.org/10.1212/wnl.0000000000003690.

27. Alberda C, Gramlich L, Jones N, Jeejeebhoy K, Day AG, Dhaliwal $\mathrm{R}$, et al. The relationship between nutritional intake and clinical outcomes in critically ill patients: results of an international multicenter observational study. Intensive Care Med. 2009;35(10):1728-37. https://doi.org/10.1007/s00134-009-1567-4.

28. Elke G, Wang M, Weiler N, Day AG, Heyland DK. Close to recommended caloric and protein intake by enteral nutrition is associated with better clinical outcome of critically ill septic patients: secondary analysis of a large international nutrition database. Crit Care. 2014;18(1):R29. https://doi.org/10.1186/cc13720.

29. Harvey SE, Parrott F, Harrison DA, Bear DE, Segaran E, Beale $\mathrm{R}$, et al. Trial of the route of early nutritional support in critically ill adults. N Engl J Med. 2014;371(18):1673-84. https://doi.org/10.1056/ NEJMoa1409860.

30. Charles EJ, Petroze RT, Metzger R, Hranjec T, Rosenberger LH, Riccio LM, et al. Hypocaloric compared with eucaloric nutritional support and its effect on infection rates in a surgical intensive care unit: a randomized controlled trial. Am J Clin Nutr. 2014;100(5):1337-43. https://doi.org/10.3945/ajcn. 114.088609 .

31. Heidegger CP, Berger MM, Graf S, Zingg W, Darmon P, Costanza $\mathrm{MC}$, et al. Optimisation of energy provision with supplemental parenteral nutrition in critically ill patients: a randomised controlled clinical trial. Lancet. 2013;381(9864):385-93. https://doi.org/10.1016/ s0140-6736(12)61351-8.

32. Singer P, Anbar R, Cohen J, Shapiro H, Shalita-Chesner $\mathrm{M}$, Lev $\mathrm{S}$, et al. The tight calorie control study (TICACOS): a prospective, randomized, controlled pilot study of nutritional support in critically ill patients. Intensive Care Med. 2011;37(4):601-9. https://doi. org/10.1007/s00134-011-2146-z.

33. Doig GS, Simpson F, Sweetman EA, Finfer SR, Cooper DJ, Heighes PT, et al. Early parenteral nutrition in critically ill patients with short-term relative contraindications to early enteral nutrition: a randomized controlled trial. Jama. 2013;309(20):2130-8. https://doi. org/10.1001/jama.2013.5124.

34. Rice TW, Wheeler AP, Thompson BT, de Boisblanc BP, Steingrub J, Rock P. Enteral omega-3 fatty acid, gamma-linolenic acid, and antioxidant supplementation in acute lung injury. Jama. 2011;306(14):1574-81. https://doi.org/10.1001/ jama.2011.1435.

35. Rice TW, Wheeler AP, Thompson BT, Steingrub J, Hite $\mathrm{RD}$, Moss $\mathrm{M}$, et al. Initial trophic vs full enteral feeding in patients with acute lung injury: the EDEN randomized trial. Jama. 2012;307(8):795-803. https://doi. org/10.1001/jama.2012.137.

36. Arabi YM, Aldawood AS, Haddad SH, Al-Dorzi HM, Tamim HM, Jones G, et al. Permissive underfeeding or standard enteral feeding in critically ill adults. N Engl J Med. 2015;372(25):2398-408. https://doi.org/10. 1056/NEJMoa1502826.

37. Casaer MP, Mesotten D, Hermans G, Wouters PJ, Schetz M, Meyfroidt G, et al. Early versus late parenteral nutrition in critically ill adults. N Engl J Med. 2011;365(6):506-17. https://doi.org/10.1056/ NEJMoa1102662.

38. Reignier J, Mercier E, Le Gouge A, Boulain T, Desachy A, Bellec F, et al. Effect of not monitoring residual gastric volume on risk of ventilator-associated pneumonia in adults receiving mechanical ventilation and early enteral feeding: a randomized controlled trial. Jama. 2013;309(3):249-56. https://doi.org/10.1001/jama. 2012.196377.

39. Klein P, Tyrlikova I, Mathews GC. Dietary treatment in adults with refractory epilepsy: a review. Neurology. 2014;83(21):1978-85. https://doi.org/10.1212/wnl. 0000000000001004.

40. Rho JM. How does the ketogenic diet induce antiseizure effects? Neurosci Lett. 2017;637:4-10. https:// doi.org/10.1016/j.neulet.2015.07.034.

41. Greene AE, Todorova MT, McGowan R, Seyfried TN. Caloric restriction inhibits seizure susceptibility in epileptic EL mice by reducing blood glucose. Epilepsia. 2001;42(11):1371-8. https://doi.org/10.1046/j.15281157.2001.17601.x.

42. McDougall A, Bayley M, Munce SE. The ketogenic diet as a treatment for traumatic brain injury: a scoping review. Brain Inj. 2018;32(4):416-22. https://doi.org/ 10.1080/02699052.2018.1429025.

43. Levy RG, Cooper PN, Giri P. Ketogenic diet and other dietary treatments for epilepsy. Cochrane Database Syst Rev. 2012(3):Cd001903. https://doi.org/10.1002/ 14651858.CD001903.pub2.

44. Martin K, Jackson CF, Levy RG, Cooper PN. Ketogenic diet and other dietary treatments for epilepsy. Cochrane Database Syst Rev. 2016;2:Cd001903. https://doi.org/10.1002/14651858.CD001903.pub3.

45. Ye F, Li XJ, Jiang WL, Sun HB, Liu J. Efficacy of and patient compliance with a ketogenic diet in adults with intractable epilepsy: a meta-analysis. J Clin Neurol. 2015;11(1):26-31. https://doi.org/10.3988/jcn.2015. 11.1.26.

46. Mahmoud SH, Ho-Huang E, Buhler J. Systematic review of ketogenic diet use in adult patients with status epilepticus. Epilepsia Open. 2020;5(1):10-21. https:// doi.org/10.1002/epi4.12370. 
47. Zinöcker MK, Lindseth IA. The Western dietmicrobiome-host interaction and its role in metabolic disease. Nutrients. 2018;10(3). https://doi.org/10. 3390/nu10030365.

48. Bailey MA, Holscher HD. Microbiome-mediated effects of the Mediterranean diet on inflammation. Adv Nutr. 2018;9(3):193-206. https://doi.org/10.1093/ advances/nmy013.

49. Hills RD Jr, Pontefract BA, Mishcon HR, Black CA, Sutton SC, Theberge CR. Gut microbiome: profound implications for diet and disease. Nutrients. 2019;11(7). https://doi.org/10.3390/nu11071613.

50. McCarthy MS, Martindale RG. Immunonutrition in critical illness: what is the role? Nutr Clin Pract. 2018;33(3):348-58. https://doi.org/10.1002/ncp. 10102.

51. Roehl K. Immunonutrition in 2016: benefit, harm or neither. Pract Gastroenterol. 2016;154:27.

52. Vonder Haar C, Peterson TC, Martens KM, Hoane MR. Vitamins and nutrients as primary treatments in experimental brain injury: clinical implications for nutraceutical therapies. Brain Res. 1640;2016:114-29. https://doi.org/10.1016/j.brainres.2015.12.030.

53. Razmkon A, Sadidi A, Sherafat-Kazemzadeh E, Mehrafshan A, Jamali M, Malekpour B, et al. Administration of vitamin $\mathrm{C}$ and vitamin $\mathrm{E}$ in severe head injury: a randomized double-blind controlled trial. Clin Neurosurg. 2011;58:133-7. https://doi.org/10.1227/neu. 0b013e3182279a8f.

54. Gupta A, Prabhakar S, Modi M, Bhadada SK, Kalaivani $\mathrm{M}$, Lal V, et al. Effect of Vitamin D and calcium supplementation on ischaemic stroke outcome: a randomised controlled open-label trial. 2016;70(9):764-70. https://doi.org/10.1111/ijcp.12866.

55. Aminmansour B, Asnaashari A, Rezvani M, Ghaffarpasand F, Amin Noorian SM, Saboori M et al. Effects of progesterone and vitamin D on outcome of patients with acute traumatic spinal cord injury; a randomized, double-blind, placebo controlled study.

2016:160201235253003. https://doi.org/10.1080/ 10790268.2015 .1114224$.

56. Zhang C, Zhao S, Zang Y, Zhao W, Song Q, Feng S, et al. Magnesium sulfate in combination with nimodipine for the treatment of subarachnoid hemorrhage: a randomized controlled clinical study. Neurol Res. 2018;40(4):283-91. https://doi.org/10.1080/ 01616412.2018.1426207.

57. Yarar-Fisher C, Kulkarni A, Li J, Farley P, Renfro C, Aslam $\mathrm{H}$ et al. Evaluation of a ketogenic diet for improvement of neurological recovery in individuals with acute spinal cord injury: a pilot, randomized safety and feasibility trial. Spinal Cord Ser Cases. 2018;4(1). https://doi.org/10.1038/s41394-018-0121-4.

58. Falcão de Arruda IS, de Aguilar-Nascimento JE. Benefits of early enteral nutrition with glutamine and probiotics in brain injury patients. Clin Sci (Lond). 2004;106(3):287-92. https://doi.org/10.1042/ cs20030251.
59. Rai VRH, Phang LF, Sia SF, Amir A, Veerakumaran JS, Kassim MKA et al. Effects of immunonutrition on biomarkers in traumatic brain injury patients in Malaysia: a prospective randomized controlled trial. BMC Anesthesiol. 2017:17(1). https://doi.org/10. 1186/s12871-017-0369-4.

60. Yoneda H, Shirao S, Nakagawara J, Ogasawara K, Tominaga T, Suzuki M. A prospective, multicenter, randomized study of the efficacy of eicosapentaenoic acid for cerebral vasospasm: the EVAS study. World Neurosurg. 2014;81(2):309-15.

61. Nakagawa I, Yokoyama S, Omoto K, Takeshima Y, Matsuda R, Nishimura F, et al. $\omega-3$ fatty acids ethyl esters suppress cerebral vasospasm and improve clinical outcome following aneurysmal subarachnoid hemorrhage. World Neurosurg. 2017;99:457-64. https://doi.org/10.1016/j.wneu.2016.12.018.

62. Strandwitz P. Neurotransmitter modulation by the gut microbiota. Brain Res. 2018;1693(Pt B):128-33. https://doi.org/10.1016/j.brainres.2018.03.015.

63. Sudo N, Chida Y, Aiba Y, Sonoda J, Oyama N, Yu XN, et al. Postnatal microbial colonization programs the hypothalamic-pituitary-adrenal system for stress response in mice. J Physiol. 2004;558(Pt 1):263-75. https://doi.org/10.1113/jphysiol.2004.063388.

64. Bonaz B, Bazin T, Pellissier S. The Vagus nerve at the Interface of the microbiota-gut-brain axis. Front Neurosci. 2018;12:49. https://doi.org/10.3389/fnins.2018. 00049.

65. Bravo JA, Forsythe P, Chew MV, Escaravage E, Savignac HM, Dinan TG, et al. Ingestion of Lactobacillus strain regulates emotional behavior and central GABA receptor expression in a mouse via the vagus nerve. Proc Natl Acad Sci U S A. 2011;108(38):16050-5. https://doi. org/10.1073/pnas.1102999108.

66. Erny D, Hrabě de Angelis AL, Jaitin D, Wieghofer P, Staszewski O, David E, et al. Host microbiota constantly control maturation and function of microglia in the CNS. Nat Neurosci. 2015;18(7):965-77. https:// doi.org/10.1038/nn.4030.

67. Braniste V, Al-Asmakh M, Kowal C, Anuar F, Abbaspour A, Tóth M, et al. The gut microbiota influences blood-brain barrier permeability in mice. Sci Transl Med. 2014;6(263):263ra158. https://doi.org/10.1126/ scitranslmed.3009759.

68. Eckburg PB, Bik EM, Bernstein CN, Purdom E, Dethlefsen L, Sargent M, et al. Diversity of the human intestinal microbial flora. Science. 2005;308(5728):1635-8. https://doi.org/10.1126/ science. 1110591.

69. Annalisa N, Alessio T, Claudette TD, Erald V, de Antonino L, Nicola DD. Gut microbioma population: an indicator really sensible to any change in age, diet, metabolic syndrome, and life-style. Mediat Inflamm. 2014;2014:901308-11. https://doi.org/10.1155/ 2014/901308.

70. Bailey JD, Diotallevi M, Nicol T, McNeill E, Shaw A, Chuaiphichai $S$, et al. Nitric Oxide modulates metabolic remodeling in inflammatory macrophages 
through TCA cycle regulation and itaconate accumulation. Cell Rep. 2019;28(1):218-30.e7. https://doi. org/10.1016/j.celrep.2019.06.018.

71. Fay KT, Ford ML, Coopersmith CM. The intestinal microenvironment in sepsis. Biochim Biophys Acta Mol Basis Dis. 2017;1863(10 Pt B):2574-83. https:// doi.org/10.1016/j.bbadis.2017.03.005.

72. Fransen F, van Beek AA, Borghuis T, Aidy SE, Hugenholtz F, van der Gaast-de Jongh C, et al. Aged gut microbiota contributes to systemical inflammaging after transfer to germ-free mice. Front Immunol. 2017;8:1385. https://doi.org/10.3389/fimmu.2017. 01385.

73. Klingensmith NJ, Coopersmith CM. The gut as the motor of multiple organ dysfunction in critical illness. Crit Care Clin. 2016;32(2):203-12. https://doi.org/10. 1016/j.ccc.2015.11.004.

74. Rea K, Dinan TG, Cryan JF. The microbiome: a key regulator of stress and neuroinflammation. Neurobiol Stress. 2016;4:23-33. https://doi.org/10.1016/j.ynstr. 2016.03.001.

Review of the gut microbiome among various neurologic disorders, including role of diet in maintenance and disruption of the gut microbiome.

75. Hayakawa M, Asahara T, Henzan N, Murakami H, Yamamoto H, Mukai N, et al. Dramatic changes of the gut flora immediately after severe and sudden insults. Dig Dis Sci. 2011;56(8):2361-5. https://doi.org/10. 1007/s10620-011-1649-3.

76. Babrowski T, Romanowski K, Fink D, Kim M, Gopalakrishnan $\mathrm{V}$, Zaborina $\mathrm{O}$, et al. The intestinal environment of surgical injury transforms Pseudomonas aeruginosa into a discrete hypervirulent morphotype capable of causing lethal peritonitis. Surgery. 2013;153(1):36-43. https://doi.org/10.1016/j.surg. 2012.06.022.

77. Krezalek MA, Yeh A, Alverdy JC, Morowitz M. Influence of nutrition therapy on the intestinal microbiome. Curr Opin Clin Nutr Metab Care. 2017;20(2):131-7. https://doi.org/10.1097/mco.0000000000000348.

78. Iapichino G, Callegari ML, Marzorati S, Cigada M, Corbella D, Ferrari S, et al. Impact of antibiotics on the gut microbiota of critically ill patients. J Med Microbiol. 2008;57(Pt 8):1007-14. https://doi.org/10.1099/ jmm.0.47387-0.

79. Lankelma JM, Cranendonk DR, Belzer C, de Vos AF, de Vos WM, van der Poll T, et al. Antibiotic-induced gut microbiota disruption during human endotoxemia: a randomised controlled study. Gut. 2017;66(9):162330. https://doi.org/10.1136/gutjnl-2016-312132.

80. Ojima M, Motooka D, Shimizu K, Gotoh K, Shintani A, Yoshiya $\mathrm{K}$, et al. Metagenomic analysis reveals dynamic changes of whole gut microbiota in the acute phase of intensive care unit patients. Dig Dis Sci.

2016;61(6):1628-34. https://doi.org/10.1007/ s10620-015-4011-3.

81. Zaborin A, Smith D, Garfield K, Quensen J, Shakhsheer B, Kade M, et al. Membership and behavior of ultralow-diversity pathogen communities present in the gut of humans during prolonged critical illness. mBio. 2014;5(5):e01361-14. https://doi.org/10.1128/mBio. 01361-14.

82. McDonald D, Ackermann G, Khailova L, Baird C, Heyland D, Kozar R et al. Extreme dysbiosis of the microbiome in critical illness. mSphere. 2016;1(4). https://doi.org/10.1128/mSphere.00199-16.

83. Yeh A, Rogers MB, Firek B, Neal MD, Zuckerbraun BS, Morowitz MJ. Dysbiosis across multiple body sites in critically ill adult surgical patients. Shock. 2016;46(6):649-54. https://doi.org/10.1097/shk. 0000000000000691.

84. Kigerl KA, Zane K, Adams K, Sullivan MB, Popovich PG. The spinal cord-gut-immune axis as a master regulator of health and neurological function after spinal cord injury. Exp Neurol. 2020;323:113085.

85. Nicholson SE, Watts LT, Burmeister DM, Merrill D, Scroggins S, Zou Y, et al. Moderate traumatic brain injury alters the gastrointestinal microbiome in a timedependent manner. Shock. 2019;52(2):240-8.

86. Yuen KCJ, Masel BE, Reifschneider KL, Sheffield-Moore M, Urban RJ, Pyles RB. Alterations of the GH/IGF-I axis and gut microbiome after traumatic brain injury: a new clinical syndrome? J Clin Endocrinol Metab. 2020;105(9). https://doi.org/10.1210/clinem/ dgaa398.

87. Wan X, Bi J, Gao X, Tian F, Wang X, Li N, et al. Partial enteral nutrition preserves elements of gut barrier function, including innate immunity, intestinal alkaline phosphatase (IAP) level, and intestinal microbiota in mice. Nutrients. 2015;7(8):6294-312. https://doi. org/10.3390/nu7085288.

88. Levesque CL, Turner J, Li J, Wizzard P, St Pierre B, Lim $\mathrm{D}$, et al. In a neonatal piglet model of intestinal failure, administration of antibiotics and lack of enteral nutrition have a greater impact on intestinal microflora than surgical resection alone. JPEN J Parenter Enteral Nutr. 2017;41(6):938-45. https://doi.org/10.1177/ 0148607115626903.

89. Ralls MW, Demehri FR, Feng Y, Woods Ignatoski KM, Teitelbaum DH. Enteral nutrient deprivation in patients leads to a loss of intestinal epithelial barrier function. Surgery. 2015;157(4):732-42. https://doi. org/10.1016/j.surg.2014.12.004.

90. Tuncay P, Arpaci F, Doganay M, Erdem D, Sahna A, Ergun $\mathrm{H}$, et al. Use of standard enteral formula versus enteric formula with prebiotic content in nutrition therapy: a randomized controlled study among neurocritical care patients. Clin Nutr ESPEN. 2018;25:26-36. https://doi.org/10.1016/j.clnesp.2018.03.123.

91. Wan G, Wang L, Zhang G, Zhang J, Lu Y, Li J, et al. Effects of probiotics combined with early enteral nutrition on endothelin-1 and C-reactive protein levels and prognosis in patients with severe traumatic brain injury. J Int Med Res. 2019;0300060519888112.

92. Sadler R, Cramer JV, Heindl S, Kostidis S, Betz D, Zuurbier KR, et al. Short-chain fatty acids improve poststroke recovery via immunological mechanisms. J Neurosci. 2020;40(5):1162-73. 
93. Carrera-Quintanar L, López Roa RI, Quintero-Fabián S, Sánchez-Sánchez MA, Vizmanos B, Ortuño-Sahagún D. Phytochemicals that influence gut microbiota as prophylactics and for the treatment of obesity and inflammatory diseases. Mediat Inflamm. 2018;2018:9734845-18. https://doi.org/10.1155/ 2018/9734845.

94. Milton DL, Johnson TW, Johnson K, Murphy B, Carter H, Hurt RT, et al. Accepted safe food-handling procedures minimizes microbial contamination of homeprepared blenderized tube-feeding. Nutr Clin Pract.
2020;35(3):479-86. https://doi.org/10.1002/ncp. 10450 .

\section{Publisher's Note}

Springer Nature remains neutral with regard to jurisdictional claims in published maps and institutional affiliations. 